\title{
Paradigm Shift in Practice: The Role of Pharmacists in COVID-19 Management
}

Samira Saghir, Furqan K Hashmi, Sitaram Khadka, Madiha Rizvi

\section{Author Info:}

Punjab University College of Pharmacy, University of the Punjab, Lahore-54000, Pakistan

Punjab University College of Pharmacy, University of the Punjab, Lahore, Pakistan

\section{Corresponding Author:}

Furqan K Hashmi

Punjab University College of Pharmacy, University of the Punjab, Lahore-54000, Pakistan

E-mail: furqan.pharmacy@ pu.edu.pk

Contact: 0092-3454194201

\section{ABSTRACT}

The continuously escalating burden of COVID-19 pandemic is challenging the health care systems around the world. The healthcare professionals of different specialties throughout the globe are working day and night for its proper mitigation. Pharmacists are healthcare professionals who are working on the frontline for the management of COVID-19 in different settings. In this review, we highlight the potential roles pharmacists can play for effective management of COVID-19. The collaborative effort of all professionals, including healthcare and other stakeholders is necessary for the appropriate management of such pandemic. Pharmacists, having expertise in clinical as well as administrative aspects, can play a pivotal role in extended health services (EHS) from prevention to eradication of COVID-19. Firm determination, inter-professional and intra-professional collaboration, and legislative support are mandatory for the rational practice of professionalism in such disasters.

Keywords: COVID-19, Disaster, Extended health service, Pharmacists, Professionalism

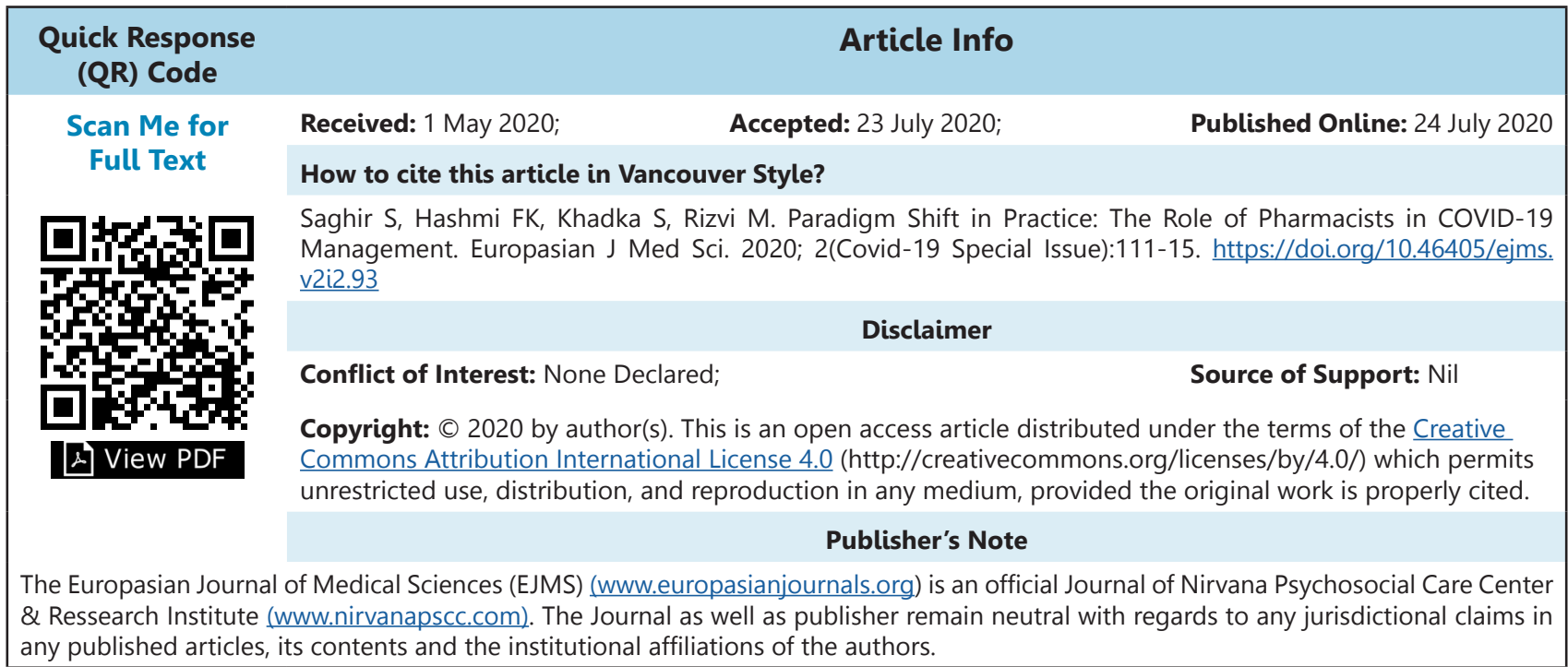




\section{INTRODUCTION}

COVID-19 pandemic is a global health crisis that has affected more than seven million people in different parts of the world and has taken a death toll over four hundred thousand to date. ${ }^{1}$ All the healthcare workers are working day and night to make the world free of COVID-19. In this regard, the pharmacists, being a healthcare practitioner, can contribute to the management based on the dynamic approaches of clinical as well as managerial tasks within the scope of their expertise. From either community level or big clinical setting; pharmacists can help in COVID-19 management taking part in preparedness and mitigation to response and recovery stages. ${ }^{2,3}$ With the continuation of the global spread of COVID-19, most of the countries, to save people, underwent lock-down that led to travel bans, closure of educational institutions, groceries, and confined people inside homes. ${ }^{4}$ In such a scenario, medication as well as counseling role becomes mandatory for the quality of life of people. ${ }^{5}$ Pharmacists, in both cases, can render their services.

Presently, pharmacy practice has been considered as one of the most essential components of healthcare practice, in collaboration with other disciplines of health science as a team for the betterment of the healthcare system. ${ }^{6}$ The American College of Clinical Pharmacy (ACCP) has defined clinical pharmacy as a health science discipline that constitutes the application by pharmacists of scientific principles of pharmacology, toxicology, pharmacokinetics, and therapeutics to patient care. ${ }^{7}$ Nowadays, with global practice, there have been different paradigm definitions that focus on bringing the quality in patients' life considering the social, psychological, and biological aspects as well. ${ }^{8}$ Pharmacists are now providing EHS like pharmaceutical care to in-patients and outpatients in clinical settings, health service outreach (HSO) programs, community-based preventive services, disaster management services, and other specialty pharmacy services besides compounding, dispensing and manufacturing practices. ${ }^{9}$

In the context of emergency preparedness of a large scale COVID-19 pandemic, the objective of the current review is to provide a panorama of services that pharmacists can render such as EHS for crisis management as a healthcare professional.

\section{METHODOLOGY}

The electronic databases like Google Scholar, PubMed, and ScienceDirect were searched using specific keywords like "Pharmacists" and "paradigm shift" or "Pharmacy practice" and "COVID-19 management" or "Disaster management" or "Extended health service" for preparing this narrative review. Related experts in the field were also consulted. Papers published in the English language were included in the review.

\section{PHARMACY PRACTICE}

Traditionally, the pharmacy profession was considered as an amalgamation of health and chemical science where pharmacists mostly worked as an apothecary, compounding, and dispensing the prescribed drugs. This concept, with the passage of time, has been modified and upgraded, which broadened the scope of practice in pharmacy. The concept of clinical pharmacy that originated in the mid-1960s has standardized the profession and marked the beginning of a rapid transition in roles of pharmacists towards more patient-oriented and gave rise to the concept of the pharmaceutical care model in the 1990s. ${ }^{10}$ Clinical drug development, clinical trials, drug therapy management as well as different EHS practices have made the profession challenging as well. The requirement of specialty degree, super-specialization, and dedicated practice in relevant fields are leading the profession towards the pinnacle for healthcare service. The paradigm shift from pharmacy practice has improved the safety and effectiveness of medicines and made significant contributions to maximize therapeutic efficacy and avoidance of medication error. ${ }^{10}$ The world health organization (WHO) also defines the mission of pharmacy practice as actively promoting health by ensuring that medications are safe, efficacious, and optimized. ${ }^{9}$ Pharmacists also carry out their professional expertise in the formulation of health strategies and health promotion for the better development of healthcare system. ${ }^{11}$

\section{Role in different disasters}

Pharmacists play a crucial role in all three phases of disaster management. In the pre-disaster phase, pharmacists help in preparedness and mitigation, while they play a role in the response stage in the disaster phase and can help in the response and recovery stage in the post-disaster phase as well. In this way, they give a valuable contribution to public health. Their clinical as well as managerial roles in humanitarian activities is definitely essential. ${ }^{12}$ 
Pharmacists are consistently being involved in the management of different types of natural or manmade disasters including bioterrorism over the past several decades around the globe.9,13 Pharmacists, easily integrating into such activities from the community to the central level, come up with a solution regarding health issues in different ways, which are now proved as commendable efforts. ${ }^{9}$ Pharmacists' active and consistent efforts in the management of terrorist attack - 2001 September in the USA, ${ }^{14}$ anthrax crisis - 2001in USA, ${ }^{15}$ SARS outbreak - 2003 in Canada, ${ }^{16}$ massive electricity blackout - 2004 in the Eastern seaboard of the USA and several Canadian Province, ${ }^{16}$ hurricane Katrina - August 2005 in USA, ${ }^{17}$ earthquake - March 2011 in Japan, ${ }^{18}$ Tasmanian bushfires - 2012/2013 in Australia, ${ }^{19}$ earthquake - April 2015 in Nepal, ${ }^{20}$ and the opioid crisis - 2016 in USA ${ }^{21}$ led pharmacists as one of the pillars of the healthcare system in disaster.

A Delphi study conducted by Watson KE et al, regarding the role of pharmacists in disaster, suggests the capability of pharmacists in different activities like prevention, preparedness, response, and recovery for disaster management. ${ }^{22}$ The International Pharmaceutical Federation (FIP) has also endorsed the role of pharmacists in different activities related to disaster management. ${ }^{23}$

\section{Role in COVID-19}

In the situation of a global crisis caused by COVID-19 pandemic, pharmacists from different settings such as; community, hospital, industrial, and other organizations can support the system as a vital health care provider. They remain as professionals on the frontline of public health from those settings. ${ }^{24,25}$ As the crisis is confining people within perimeter by lockdown, pharmacists being easily accessible and available in community settings can provide health services. ${ }^{26}$ The potential roles pharmacists can play in COVID-19 are depicted in figure 1.

Preventive services: Where pharmacists are providing awareness on disease containment through audio-visual media, the establishment of healthcare desks for COVID-19 services, contact tracing, and quarantine services as well. Ensuring appropriate development of emergency medicine, performing general health screening, disseminating medical information are also the steps pharmacists can adopt. $^{9}$

Triaging services: Where pharmacists classify people based on the vulnerability analysis and follow-up accordingly. They provide such services to patients in the community and clinical settings as well according to the severity and suspicion of cases into different zones, hence the need for isolation or quarantine can be determined at that time.

Supply chain management: Where they assure a consistent, easy, and rational supply of medicines and related items to people. Selecting medicine and related supplies, ensuring packaging, storage, handling, labeling, dispensing, and counseling on therapy are the appropriate measures. ${ }^{18}$

Patient compliance: Where they promote medication adherence that helps in drug therapy management.

Follow-up care and counseling: Follow-up of the presence and progression of the condition helps patients for optimizing the therapeutic outcomes. The psychological stress due to COVID-19 is to be dealt with in a proper manner as different types of stressful conditions due to the disease and measures adopted to manage the disease

may have long-term effects as a post-traumatic stress disorder. The proper counseling to patients at reqular intervals from community and clinical

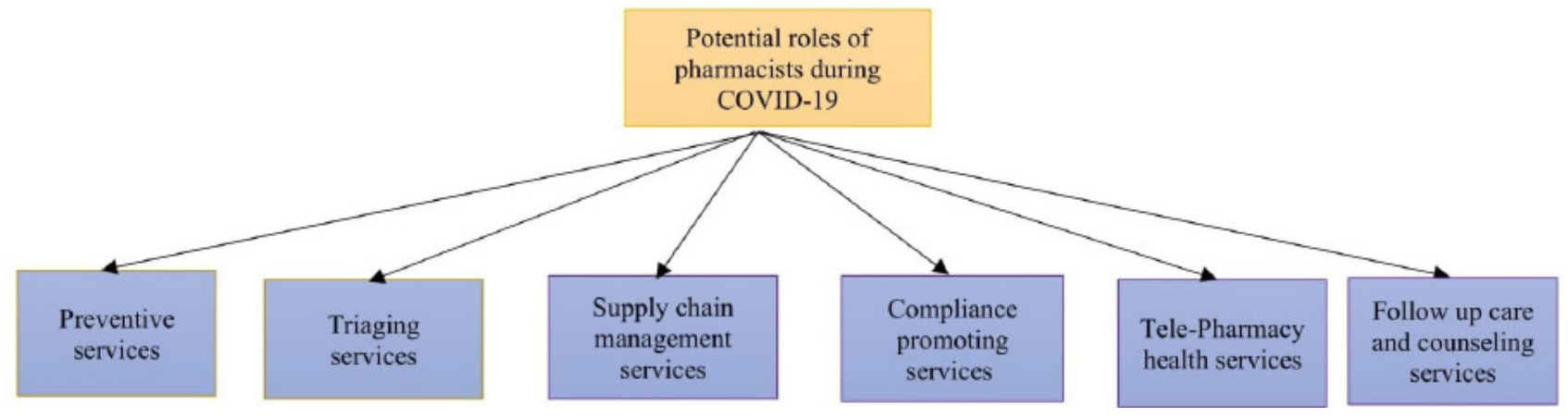

Figure 1: Flow chart representing the potential roles of pharmacists during COVID-19 
settings can be helpful and pharmacists can provide such services effectively.

Tele-pharmacy health services: This is a relatively new concept as far as pharmacy services are concerned and are of much importance in such a crisis where the lockdown has restricted the movement of people. Therefore, pharmacists can provide services through multimedia health education, tele-medicine, remote inpatient order reviews, multidisciplinary treatments, and telepharmaceutical care as well. ${ }^{11}$ With this approach, pharmacists can render services ranging from prevention to cure.

\section{Limitation}

The lack of training and curriculum related to disaster management practice in the pharmacy field is the key point attributing to less involvement of pharmacists in crisis management. ${ }^{27}$ Despite the paradigm shift of practice, most of the pharmacists are involved in traditional roles. Due to this, a layman concept may arise in the mind of people regarding the specialty and nature of the work of pharmacists. Moreover, ingeneral, people still regard pharmacists as a drug seller or dispenser and may not include as an important part in the healthcare team, consequently leading to unwillingness in active participation in some cases. The need of different stakeholders to advocate policy-makers for legislative support may help pharmacists to get recognition and to undertake specific roles in different types of disaster management such as; COVID-19 cases within a specific jurisdiction.

\section{CONCLUSION}

The escalating COVID-19 burden due to a continuous rise in cases can be tackled by the collaborative effort of a team composed of all healthcare professionals, locals, and other stakeholders within one umbrella. Pharmacists can play a significant role in this regard with their expertise in clinical and managerial aspects. Education and practice with a firm determination along with legislative support from policymakers are crucial factors for maximizing the standard of care and responsibility of pharmacists in such scenarios.

\section{Recommendations}

The education and practice regarding disaster management in the curriculum of pharmacy is necessary. Pharmacists must demonstrate professionalism as a healthcare professional with knowledge, practice, determination, and inter-as well as intra-professional collaboration.
Preparedness practice, training, and mock-drills should be conducted regularly with the formation of ad hoc teams such as disaster management response teams considering the fact that "nothing happens until it doesn't happen". The team should include pharmacists and their expertise should be utilized. Legislative support for recognition and inclusion in a team is necessary.

\section{REFERENCES}

1. Coronavirus (COVID-19). WHO. https://who.sprinklr. com/. Published 2020. Accessed July 5, 2020. [Link]

2. Pincock LL, Montello MJ, Tarosky MJ, Pierce WF, Edwards CW. Pharmacist readiness roles for emergency preparedness. Am J Heal Pharm. 2011;68(7):620-623. https://doi.org/10.2146/ ajhp090659 [Google Scholar] [PubMed]

3. Khan, H., Vasilescu, L. G., \& Khan A. Disaster management cycle-a theoretical approach. J Manag Mark. 2008;6(1):43-50. [Google Scholar]

4. Budhathoki P, Shrestha DB, Khadka S, Giri S. COVID-19 Status in Nepal and the Way Forward. Eur J Med Sci. 2020;2(2). https://doi.org/10.46405/ejms. v2i2.75 [Google Scholar]

5. Sajed AN, Amgain K. Corona Virus Disease (COVID-19) Outbreak and the Strategy for Prevention. Eur J Med Sci. 2020;2(1):1-4. https://doi.org/10.46405/ejms. v2i1.38 [Google Scholar]

6. Pearson GJ. Evolution in the practice of pharmacynot a revolution! Cmaj. 2007;176(9):1295-1296. https://doi.org/10.1503/cmaj.070041 [Google Scholar] [PubMed]

7. Hepler CD. Clinical pharmacy, pharmaceutical care, and the quality of drug therapy. Pharmacotherapy. 2004;24(11):1491-1498. https://doi.org/10.1503/ cmaj.070041 [Google Scholar] [PubMed]

8. Hassali MA, Hashmi FK, Al-Tamini SK. Defining clinical pharmacy: a new paradigm. The Pharmaceutical Journal. 2016; 297:7894. https://doi.org/10.1211/ PJ.2016.20201798 [Google Scholar]

9. Moore AF, Kenworthy L. Disaster Relief A Look Into the Pharmacist's Role. N C Med J. 2017;78(3):195197. https://doi.org/10.18043/ncm.78.3.195 [Google Scholar] [PubMed]

10. Khadka, S., Hashmi, FK., Malik, UR., Rizvi, M., Kunwar B., \& Singh, KB. Clinical Pharmacy Practice in Nepal; Current Scenario and the Way Forward. Perspective, 3(1). Pharm Drug Regul Aff J. 2019;3(1). [Google Scholar]

11. Li H, Zheng S, Liu F, Liu W, Zhao R. Fighting against COVID-19: innovative strategies for clinical pharmacists. Res Soc Adm Pharm. 2020. https:// doi.org/10.1016/j.sapharm.2020.04.003 [Google 
Scholar] [PubMed]

12. Hassali MA, Dawood OT, Al-Tamimi SK, Saleem F. Role of pharmacists in health based nongovernmental organizations (NGO): prospects and future directions. Pharm Anal Acta. 2016;7(2):467. [Google Scholar] [PubMed]

13. Ford $\mathrm{JH}$. Pharmacists in disasters (Doctoral dissertation, University of Georgia). 2013. [Google Scholar]

14. Armitstead JA, Burton DC. Enhanced pharmacy training for counter-terrorism and disaster response. J Telemed Telecare. 2006;12(1_suppl):3-5. https:// doi.org/10.1258/135763306777978498 [Google Scholar] [PubMed]

15. Montello MJ, Ostroff C, Frank EC, Haffer AST, James R R. 2001 anthrax crisis in Washington, DC: Pharmacists' role in screening patients and selecting prophylaxis. Am J Heal Pharm. 2002;59(12):11931199. https://doi.org/10.1093/ajhp/59.12.1193 [Google Scholar] [PubMed]

16. Austin Z, Martin JC, Gregory PAM. Pharmacy practice in times of civil crisis: the experience of SARS and "the blackout" in Ontario, Canada. Res Soc Adm Pharm. 2007;3(3):320-335. https://doi.org/10.1016/j. sapharm.2006.09.001 [Google Scholar] [PubMed]

17. Velazquez L, Dallas $S$, Rose $L$, et al. A PHS pharmacist team's response to Hurricane Katrina. Am J Heal Pharm. 2006;63(14):1332-1335. https://doi. org/10.2146/ajhp060020 [Google Scholar] [PubMed]

18. Takeda Y. A report from Japan: disaster relief efforts of pharmacists in response to the Great East Japan Earthquake. SA Pharm J. 2011;78(9):42-46. [Google Scholar]

19. Mak PW, Singleton J. Burning questions: Exploring the impact of natural disasters on community pharmacies. Res Soc Adm Pharm. 2017;13(1):162171. https://doi.org/10.1016/j.sapharm.2015.12.015 [Google Scholar] [PubMed]

20. Kato A, Wakushima $H$, Mannen $T$, Egawa T.
Participation of the Pharmacist in the Disaster Responses for the Nepal Earthquake Disaster. Iryo Yakugaku (Japanese J Pharm Heal Care Sci. 2016;42(5):356-363. jjphcs.42.356 [Google Scholar]

21. Compton WM, Jones CM, Stein JB, Wargo EM. Promising roles for pharmacists in addressing the US opioid crisis. Res Soc Adm Pharm. 2019;15(8):910916. https://doi.org/10.1016/j.sapharm.2017.12.009 [Google Scholar] [PubMed]

22. Watson KE, Singleton JA, Tippett $V$, Nissen LM. Defining pharmacists' roles in disasters: A Delphi study. PLoS One. 2019;14(12). https://doi. org/10.1371/journal.pone.0227132 [Google Scholar] [PubMed]

23. Lowe R. Roles and regulations for pharmacists in state-level disaster relief efforts. 2014. http://thesis. honors.olemiss.edu/191/. [Google Scholar]

24. Cadogan CA, Hughes CM. On the frontline against COVID-19: Community pharmacists' contribution during a public health crisis. Res Soc Adm Pharm. 2020. https://doi.org/10.1016/j. sapharm.2020.03.015 [Google Scholar] [PubMed]

25. Khadka S, Hashmi FK, Usman M. Preventing COVID-19 in low- and middle-income countries. Drugs Ther Perspect. 2020. doi:10.1007/s40267020-00728-8. https://doi.org/10.1007/s40267-02000728-8 [Google Scholar] [PubMed]

26. Bukhari N, Rasheed H, Nayyer B, Babar Z-U-D. Pharmacists at the frontline beating the COVID-19 pandemic. 2020. https://doi.org/10.1186/s40545020-00210-w [Google Scholar] [PubMed]

27. Alkhalili, M., Ma, J., \& Grenier S. Defining roles for pharmacy personnel in disaster response and emergency preparedness. Disaster Med Public Health Prep. 2017;11(4):496-504. https://doi.org/10.1017/ dmp.2016.172 [Google Scholar] [PubMed] 